\title{
COMMENTARY
}

\section{Institutionalizing Community Health Services in Kenya: A Policy and Practice Journey}

\author{
Salim Hussein, ${ }^{a}$ Lilian Otiso, ${ }^{b}$ Maureen Kimani, ${ }^{a}$ Agatha Olago, ${ }^{a}$ John Wanyungu, ${ }^{a}$ Daniel Kavoo,

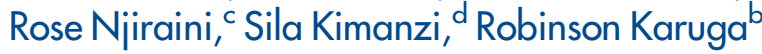

\section{Key Messages}

- Institutionalizing community health services is a long journey that involves developing relevant policy documents that align with national and global priorities and have the support of political stakeholders.

- A legal framework and continuous engagement with leaders of subnational units is important to ensure standardization, institutionalization, and financing of policies.

- Policy should be informed by evidence generated from within the country to understand what is working well and address challenges that may limit implementation.

- Engage multiple stakeholders to use a multisectoral approach and to harness their various strengths to support policy development.

\section{INTRODUCTION}

K

enya has made tremendous progress in institutionalizing community health services at the policy and practice level. The last 5 years have been particularly instrumental as this period also coincided with key changes globally and in Kenya. Globally, the push for universal health coverage (UHC) since the United Nations declaration of $2012^{1}$ and the refocus on primary health care (PHC) from the Alma Ata declaration of $1978^{2}$ and the Astana declaration of $2018^{3}$ has been instrumental in informing Kenya's more recent policy priorities as the country signed onto them.

In 2017, the Kenyan President made UHC a priority as part of the Big Four Agenda for development ${ }^{4,5}$ to ensure all Kenyans could access the services they required

\footnotetext{
${ }^{a}$ Kenya Ministry of Health, Nairobi, Kenya.

b LVCT Health, Nairobi, Kenya.

c Kenya Country Office, United Nations Children's Fund, Nairobi, Kenya.

d U.S. Agency for International Development, Nairobi, Kenya.

Correspondence to Lilian Otiso (lilian.otiso@lvcthealth.org).
}

without experiencing financial hardship. This progress would not have been possible without strong government leadership and a strong partnership and engagement with devolved subnational governments, referred to as counties and other stakeholders.

In Kenya, community health volunteers (CHVs) are key for delivery of PHC services and UHC. This cadre of lay health workers gained prominence after the Alma Ata Declaration of $1978 .^{2}$ In response to declining health indicators from the 1990s, Kenya's Ministry of Health $(\mathrm{MOH})$ first launched the Community Health Strategic Plan in 2006 (Figure). ${ }^{6}$ The strategic plan focused on providing community level health services for all, building the capacity of the community health extension workers (CHEWs), strengthening health facility-community linkages, and strengthening the community to progressively realize their rights for accessible and quality care.

In 2014, the MOH operationalized the second national health sector strategic plan (2014-2019), ${ }^{7}$ which aimed to further reverse declining health indicator trends. This revised strategy focused on improving the delivery of integrated, comprehensive, and quality community health services for all population cohorts; strengthening data demand and information use at all levels; and bolstering mechanisms for resource mobilization and management for sustainable implementation of community health services. Community units-identified as the basic geographical unit for delivery of basic health services (health prevention, promotion and education, targeted disease prevention, and basic curative services)-comprised 5,000 people or 1,000 households. Each community unit was served by CHVs that were supervised by CHEWs. ${ }^{7}$ The second strategy also addressed gaps in attrition of CHVs and recognizing the heterogeneity of the country when implementing the strategy.

Despite having a revised strategy, the implementation of full community health services at the county level was hampered by lack of a community health policy that served as a legal framework. ${ }^{8}$

This article is based on reflections of the policy makers (leadership of the Division of Community Health in the $\mathrm{MOH})$, donors, and implementing partners who were involved in the processes that have led to institutionalizing the 
FIGURE. Evolution of the Community Health Strategy in Kenya

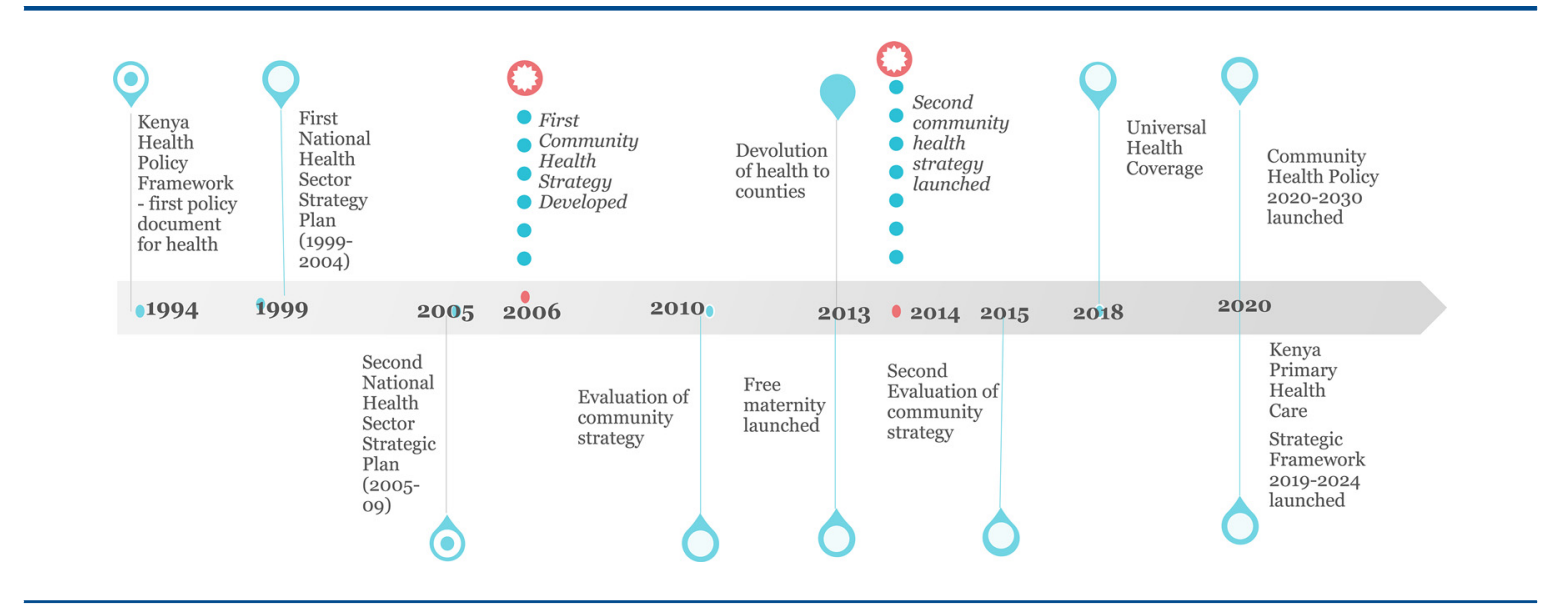

community health services. We describe how development of the community health policy has contributed to institutionalization of community health services and increased the visibility of the community strategy as a key pillar toward achieving the UHC and PHC priorities in Kenya.

\section{THE COMMUNITY HEALTH POLICY}

In July 2020, Kenya launched its first Community Health Policy 2020-2030 ${ }^{8}$ alongside the Primary Health Care Strategic Framework 2019-2024 ${ }^{9}$ at an event led by the Cabinet Secretary for Health in recognition of the key role that CHVs play in delivering PHC services.

The policy's key objectives are to provide guidance for establishing and implementing a strong, comprehensive, integrated, equitable, holistic, and sustainable community health structure in

The varying implementation of Kenya (Table). The policy provides the legal the community strategy and changes to the legal policy framework highlighted the need for a national community health policy. issues such as recruitment, remuneration, trainframework to facilitate implementation and achievement of $100 \%$ coverage with community units and recognition of community health personnel by the counties. This policy addresses ing, and deployment of the community health workforce and a stronger community health information system.

\section{Key Factors That Contributed to the Successful Establishment of the Policy}

We identified 4 factors that had the most significance in ensuring successful policy development and ensuring progress in institutionalizing community health services. These factors were the result of reflection and iteration of various factors that arose during the writing of the article.

\section{The Importance of Context (Devolution) Decentralization)}

In 2013, Kenya devolved health and other services from the central government to 47 new subnational governments known as counties, which are semiautonomous units responsible for implementation of health services. The national government is responsible for training and development of policies and guidelines. Devolution presented a number of challenges, ${ }^{10,11}$ including the differences in how counties implemented the second 2014-2019 community strategy. Some county leaders did not recognize the CHVs' role in the health system. Other counties developed their own models of the strategy and overhauled the entire program with varying levels of success. ${ }^{12}$ Some counties served as model counties by establishing mechanisms for remunerating CHVs (Siaya County), and others adapted the strategy to prioritize their health needs. ${ }^{13}$ The varying implementation of the community strategy highlighted to the national $\mathrm{MOH}$ the urgent need for development of a national community health policy in response to the changes to the legal policy and institutional framework governing the health sector. This policy would be informed by county priorities and would enable buy-in and implementation by counties.

\section{Evidence-based Policy Making}

Community health policy and guidelines development in Kenya has been informed by research and 
TABLE. Summary of the Community Health Policy Objectives, Kenya ${ }^{6}$

\begin{tabular}{|c|c|}
\hline General Objective & $\begin{array}{l}\text { To provide policy guidance for the establishment and implementation of a } \\
\text { strong, equitable, holistic, and sustainable community health structure }\end{array}$ \\
\hline \multicolumn{2}{|l|}{ Specific Policy Objectives } \\
\hline 1. Leadership and Governance & $\begin{array}{l}\text { Secure effective leadership and governance in the formation, maintenance, } \\
\text { and management of community health structures and participation } \\
\text { mechanisms }\end{array}$ \\
\hline 2. Community Health Workforce & $\begin{array}{l}\text { Ensure the recruitment and retention of community health human resources } \\
\text { for health, including obtaining appropriate numbers and strengthening } \\
\text { mechanisms for capacity building and supportive supervision of community } \\
\text { health personnel }\end{array}$ \\
\hline 3. Service Delivery & $\begin{array}{l}\text { As per the community health strategy, ensure provision of high-quality } \\
\text { community health services at the household and community level, including } \\
\text { referral and follow-up services }\end{array}$ \\
\hline $\begin{array}{l}\text { 4. Community-Based Health Information } \\
\text { System }\end{array}$ & $\begin{array}{l}\text { Support the development and strengthening of community-based health } \\
\text { information system and the monitoring and evaluation of systems to } \\
\text { sufficiently inform the implementation of community services at all levels }\end{array}$ \\
\hline 5. Health Products and Technologies & $\begin{array}{l}\text { Promote and strengthen supply chain systems for community health that are } \\
\text { integrated into the government-led reporting systems and that link facilities } \\
\text { including the use of available technology }\end{array}$ \\
\hline 6. Financing for Community Health & $\begin{array}{l}\text { Provide various mechanisms for mobilizing, managing, and appropriately } \\
\text { allocating resources for sustainable financing and delivery of community } \\
\text { health services at all levels }\end{array}$ \\
\hline $\begin{array}{l}\text { 7. Monitoring, Evaluation, Research and } \\
\text { Community-Based Surveillance }\end{array}$ & $\begin{array}{l}\text { Provide for community health services and human resources data and } \\
\text { knowledge management that will inform evidence-driven decision making }\end{array}$ \\
\hline
\end{tabular}

evaluations conducted by the MOH in partnership with various stakeholders. The first strategy (2006) was informed by implementation research that demonstrated improved health indicators due to work performed by CHVs. After the first 5 years of scale-up, a countrywide evaluation revealed that the strategy was successful in improving indicators such as hygiene, sanitation, uptake of antenatal care services, and child health (immunization and diarrhea). The evaluation also identified high $\mathrm{CHV}$ attrition due to lack of a reward or remuneration system, inadequate empowerment of community members, and weak accountability and governance structures. $^{14}$

After this evaluation, the 2014-2019 community strategy was defined, recognizing the challenge of nonremunerated CHVs and proposing a monthly stipend equivalent to US\$20. It proposed a new structure for the community unit with fewer CHVs and 5 CHEWs who could provide health promotion and basic curative services at the household level. The revised strategy also recognized the need for adaptation of the strategy based on the diverse socioeconomic and ecological contexts seen in the country (i.e., urban, agrarian, nomadic, and pastoralist communities). ${ }^{7}$ In 2015 , various stakeholders in all counties conducted a national evaluation that provided the evidence demonstrating the need for a community health policy, due to the lack of a legislative framework, that counties could use to advocate for and budget for $\mathrm{CHV}$ remuneration and other CHS costs. ${ }^{15}$

A 2018 national assessment of the community health strategy in the 47 counties (unpublished) found that most counties did not have specific community health policies or guidelines, and they relied on the national guidelines and the constitution to guide their community health planning. About 10 counties had a community health bill (legislation to recognize CHVs in law). About two-thirds of the counties reported allocating funds for community health, albeit inadequate. A third of the counties reported providing financial incentives to CHVs although this was inconsistent. The assessment identified challenges related to the varied implementation of community strategy across counties: varying number of CHVs per community unit, training, and supervision structures; lack of budgetary allocation and proper utilization of funds for community health in most counties 


The action plan
helped to
synergize and
catalyze efforts
toward
strengthening
and institutional-
izing community
health services in
Kenya by all
stakeholders.

stakeholders. with reliance on donors or nongovernmental organizations (NGOs) in others; low quality of community health services due to lack of training, commodities, supervision, and quality improvement of CHWs; and poor coordination of partners/stakeholders including funders at the county level. Finally, lack of a legal framework to sustain the funding for community health services at the national or county level was a common and urgent problem similar to that identified in the 2015 evaluation and informed the need to expedite finalization of the community health policy that had been in development since 2016 .

\section{Stakeholders' Engagement}

The policy's development and launch was a result of concerted efforts since 2016 by many stakeholders, including the county governments and partners led by the $\mathrm{MOH}$. The community health program has benefited from support from various stakeholders at the national and subnational levels including development partners such as United Nations Children's Fund (UNICEF), U.S. Agency for International Development (USAID), NGOs, religious bodies, community-based organizations, and community leaders. This has been in line with recommendations from various global guidelines. ${ }^{16,17}$

In 2017, Kenya's MOH officials and stakeholders, including UNICEF, USAID, and NGO representatives that are members of the Community Health Technical Working Group, attended the first Institutionalizing Community Health Conference in Johannesburg, South Africa. This delegation developed an action plan toward institutionalizing community health in Kenya, reflecting on progress made, key challenges, and priorities for achieving goals based on their knowledge of the Kenyan community health landscape.

The stakeholders set 3 priority objectives that have contributed to the institutionalization of community health described in this article.

1. Finalize the Community Health Services Policy: The progress had begun in 2016 but had stalled and needed engagement with counties for input and finalization.

2. Conduct an assessment/evaluation of Kenya's community health services: Although the revised community strategy had been launched in 2014, it had been developed prior to devolution and was due for a review that would meet the varying needs of counties. This process informed an evaluation in 2018 that is being used to revise the strategy that is ongoing at the time of submission of this article.

3. Increase the visibility of community health services: Stakeholders felt that community health services in Kenya were not prioritized beyond the Division of Community Health Services or adequately financed by the $\mathrm{MOH}$ and other donors ${ }^{14}$ despite being in existence and mentioned in several government policy documents since 2006. At the time of the conference, the $\mathrm{MOH}$ Community Health and Development Unit only received salaries from the government and completely relied on donors and NGOs to conduct operational activities in their work plans. In addition, although the community strategy had been in place since 2006, it was not recognized, integrated, or budgeted for across all program areas and priority government initiatives, including Linda Mama (free maternal health care) and UHC programs that had been rolled out by the government. The stakeholders agreed to utilize all opportunities to advocate for CHWs in all programs.

The action plan helped to synergize and catalyze efforts toward strengthening and institutionalizing community health services in Kenya by all stakeholders. The MOH Division of Community Health Services regularly convened stakeholders through technical working groups to conduct a national evaluation of the community strategy and support the development of the policy and other relevant policy documents and guidelines. Throughout all these processes, county governments were engaged to provide input into the development as they are responsible for the implementation of the community health strategy in the county. The result has been national documents that have input from a wide range of stakeholders and are likely to be sustained.

\section{Political Leadership and Alignment with Political Priorities}

The role of politics in informing health policies and financing cannot be understated. ${ }^{18}$ The stakeholders involved in developing the community health policy recognized that for community health to be integrated and institutionalized in the health system in Kenya, there had to be buyin from the top government leadership. They identified opportunities or policy windows ${ }^{19}$ that had presented themselves to support recognition of the community strategy. The most important was the UHC agenda. 
As part of the Kenya President's Big Four Agenda for development 2017-2022, the UHC agenda aims to ensure affordable and quality health care for all and specifically mentions scaling up CHVs as a priority initiative. The Cabinet Secretary for Health attended the Global Conference on Primary Health Care in Astana, Kazakhstan, in October 2018, and Kenya endorsed the declaration on PHC that prioritized working with CHWs. ${ }^{20}$ The Primary Health Care Strategy 2019-2024, which incorporates CHVs as members of the multidisciplinary team at the PHC level, is set to drive the UHC agenda in Kenya. ${ }^{9}$ The Cabinet Secretary for Health has committed to prioritize institutionalization and integration of community health in all health policies.

The 47 county governments have all endorsed the UHC agenda, the Primary Health Care Strategy, and the Community Health Policy as a result of the political buy-in from the President and the Cabinet Secretary for Health. This has resulted in increased commitments from counties to prioritize and budget for CHVs and other community health cadres in their counties.

\section{Milestones in the Journey to Institutionalizing Community Health Services}

The consultative process of developing the Community Health Policy began in 2016 and was completed in 2020 following several consultative meetings with the county governments. Other policy level events happened in tandem, which strengthened the community health system and advocacy. First, finalization of the National Kenya Health $\mathrm{Act}^{21}$ institutionalized the community level as tier 1 in the health system. Second, publication of the Investment Case for Community Health Services demonstrated a 9.4 to 1 return on investment when Kenya invests in community health services. ${ }^{22}$ This was similar to global investment cases that showed that investing in community health can generate up to 10 times return on investment and was key to supporting advocacy efforts to finance community health at the national and county government level. ${ }^{23}$ To ensure quality of CHW programs, the USAID SQALE project developed a mechanism for implementing quality improvement at the community level by adapting the Kenya Quality Model for Health. ${ }^{24}$

Some of the key milestones to date that resulted from the processes undertaken by the $\mathrm{MOH}$ and its stakeholders to institutionalize community health in the health system are described here.

1. The CHVs have played a significant role in the coronavirus disease (COVID-19) pandemic response in Kenya. ${ }^{25}$ With training and support from the $\mathrm{MOH}$ and stakeholders, they have supported infection prevention control, contact tracing, and home-based care. This has gained them recognition and special mention by the Cabinet Secretary for Health, county governors, and the President on many occasions. We anticipate that this will cement the financing of the CHW programs and further institutionalization.

2. In line with the community health strategy, the government has disbursed funds to train 31,780 CHVs to increase coverage of community units to $100 \%$ nationally. The government has also committed to train and recruit 2,000 salaried CHEWs through governmentowned Kenya medical training colleges across the country.

3. The MOH is working with the Senate on the Community Health Services Bill, ${ }^{26}$ which will anchor the community health services and formally recognize tier 1 services, giving it a legal mandate to be funded by counties. This will augment the existing county-level community health service bills that have given CHVs recognition and will allow them to earn a stipend in some counties.

4. There have been advancements in developing systems and strategies to strengthen community health services. The following are ongoing processes at the time of publication of this article: development of a revised community strategy (2020-2025) that incorporates findings from the national evaluation; development of community-based surveillance system to enhance early identification of outbreaks at community level; and digitization of the community-based health information systemelectronic CHIS (E-CHIS).

\section{Challenges in Institutionalization of Community Health Services}

Despite the gains made in institutionalizing community health in Kenya, a lot of work still needs to be done by the $\mathrm{MOH}$ and stakeholders to sustain these gains. Some of the priority activities are listed here.

- Sustained advocacy for funding for community health services from domestic sources (national and county level) by MOH staff, NGOs, and development partners. ${ }^{27}$ This will supplement the financial support received from bilateral and multilateral funders.

- Completion of the legislation processes to ensure community health services are delivered
With training and support from the MOH, CHVs played a significant role in the COVID-19 pandemic response in Kenya. 
and financed through legitimate and sustainable policy frameworks.

- Strengthening of accountability mechanisms at different government and health system levels starting with communities to demand quality and sustained primary and universal health care. $^{28}$

- Ensuring quality of community health programs by aligning them to the policy, standardized training, commodities, supervision, and quality improvement mechanisms as described in the World Health Organization guidelines on community health. ${ }^{29}$

\section{CONCLUSION}

Kenya's MOH has made significant progress in institutionalizing community health services in policy. The lessons learned on understanding context, use of evidence, meaningful engagement of stakeholders, and alignment to political priorities are important to inform successful policy engagement processes for others in a similar situation. Sustaining these gains will be a key priority for the technocrats in the $\mathrm{MOH}$ and the stakeholders to ensure CHW programs remain a political priority that is financed as a core component of the health system.

\section{REFERENCES}

1. United Nations. Resolution Adopted by the General Assembly on 12th December 2012. 67/81. Global Health and Foreign Policy. United Nations General Assembly; 2013. Accessed January 20, 2021. https://undocs.org/A/RES/67/81

2. World Health Organization (WHO). Declaration of Alma-Ata, 1978. International Conference on Primary Health Care. WHO; 1978. Accessed January 20, 2021. https://www.euro.who.int/en/ publications/policy-documents/declaration-of-alma-ata,-1978\#: : :text=Declaration\%20from\%20the\%20International\% 20 Conference,level\%20of\%20health\%20is\%20a

3. World Health Organization (WHO). Declaration of Astana. WHO; 2018. Accessed January 26, 2021. https://www.who.int/teams/ primary-health-care/conference/declaration

4. Government of Republic of Kenya. "The Big Four" - Immediate Priorities and Actions: Specific Priorities for the New Term. December 2017. Government of Kenya; 2017. http://cn.invest.go.ke/wpcontent/uploads/2018/12/Government-of-Kenya-Big-Four-Plan. pdf

5. Government of Republic of Kenya. Parliamentary Budget Office. Eye on the 'Big Four.' Budget Watch for 2018/19 and the Medium Term. Government of Republic of Kenya; 2018. Accessed January 20, 2021. http://www.parliament.go.ke/sites/default/files/2018-09/ Budget\%20Watch\%202018.pdf

6. Government of Republic of Kenya. Ministry of Health (MOH). Taking the Kenya Essential Package for Health to the Community: A Strategy for the Delivery of Level One Services. MOH; 2006. Accessed January 26, 2021. https://www.communityledtotalsanitation.org/ sites/communityledtotalsanitation.org/files/community_strategy. pdf
7. Government of Republic of Kenya. Ministry of Health $(\mathrm{MOH})$. Strategy for Community Health (2014-2019): Transforming Health: Accelerating Attainment of Health Goals. MOH; 2013. Accessed January 20, 2021. http://guidelines.health.go.ke:8000/media/ STRATEGY_FOR_COMMUNITY_HEALTH_2014-2019.pdf

8. Government of Republic of Kenya. Ministry of Health (MOH). Kenya Community Health Policy 2020-2030. MOH; 2019. Accessed January 25, 2021. https://www.health.go.ke/wp-content/ uploads/2020/07/Kenya-Community-Health-Policy-Signed.pdf

9. Government of Republic of Kenya. Ministry of Health (MOH). Kenya Primary Health Care Strategic Framework 2019-2024. MOH; 2019. Accessed January 20, 2021. https://www.health.go.ke/wpcontent/uploads/2020/07/Kenya-Primary-Healthcare-StrategicFramework-Signed.pdf

10. Mireku M, Kiruki M, McCollum R, Taegtmeyer M, de Koning K, Otiso L. Context Analysis: Close-to-Community Health Service Providers in Kenya. LVCT Health; 2014. Accessed January 20, 2021. http:// www.reachoutconsortium.org/media/1837/kenyacontextanalysis jul2014compressed.pdf

1 1. McCollum R, Otiso L, Mireku M, et al. Exploring perceptions of community health policy in Kenya and identifying implications for policy change. Health Policy Plan. 2016;31(1):10-20. CrossRef. Medline

12. Mireku M, Muturi N, Karuga R. Implementing community health services in the context of health devolution: a case study of Kitui County, Kenya. LVCT Health; 2019. Accessed January 20, 2021. https:// Ivcthealth.org/wp-content/uploads/2020/02/OP083_Mireku-etal.pdf

13. McCollum R, Theobald S, Otiso L, et al. Priority setting for health in the context of devolution in Kenya: implications for health equity and community-based primary care. Health Policy Plan. 2018;33(6): 729-742. CrossRef. Medline

14. Government of Republic of Kenya. Ministry of Health (MOH). Evaluation Report of the Community Health Strategy Implementation in Kenya. MOH; 2010. Accessed January 20, 2021. http:// guidelines.health.go.ke:8000/media/Evaluation_Report_of_the_ Community_Health_Strategy_Implementation_in_Kenya.pdf

15. Government of Republic of Kenya. Ministry of Health (MOH). Situation Analysis on the Kenya Community Health Strategy A Technical Reference Document for the Development of the Kenya Community Health Services Policy October 2015. MOH; 2015.

16. Perry H, Crigler L, Hodgins S. Developing and Strengthening Community Health Worker Programs at Scale: A Reference Guide and Case Studies for Program Managers and Policymakers. Maternal and Child Health Integrated Program; 2014. Accessed September 1, 2020. https://chwcentral.org/resources/developingand-strengthening-community-health-worker-programs-at-scale-areference-guide-and-case-studies-for-program-managers-andpolicymakers/

17. Walker PR, Downey S, Crigler L, Leban K. CHW "Principles of Practice": Guiding Principles for Non-Governmental Organizations and Their Partners for Coordinated National Scale-up of Community Health Worker Programmes. CORE Group, World Vision International; 2013. https://www.wvi.org/sites/default/files/ CHW_Principles_of_Practice_Final.pdf

18. Gore R, Parker R. Analysing power and politics in health policies and systems. Glob Public Health. 2019;14(4):481-488. CrossRef. Medline

19. Suzuki Y. Summary: John W. Kingdon, "Agendas, Alternatives, and Public Policies, Update Edition, with an Epilogue on Health Care (2nd Edition)." With a small compass blog. Published February 6, 2013. Accessed January 20, 2021. https://yuheisuzuki.wordpress.com/ 2013/02/06/summary-john-w-kingdon-agendas-alternativesand-public-policies-update-edition-with-an-epilogue-on-healthcare-2nd-edition/ 
20. Kluge H, Kelley E, Swaminathan S, et al. After Astana: building the economic case for increased investment in primary health care. Lancet. 2018;392(10160):2147-2152. CrossRef. Medline

21. Government of Republic of Kenya. Kenya Gazette Supplement, Acts 2017. The Health Act No. 21 of 2017. Published June 23, 2017. http://kenyalaw.org/kl/fileadmin/pdfdownloads/Acts/ HealthActNo.21 of2017.pdf

22. Government of Republic of Kenya. Ministry of Health (MOH). The Investment Case for Community Health in Kenya. MOH; 2018. Accessed January 20, 2021. https://livinggoods.org/wp-content/ uploads/2019/06/Investment-Case-for-Community-Health-inKenya.pdf

23. Dahn B, Woldemariam AT, Perry H, et al. Strengthening Primary Health Care through Community Health Workers: Investment Case and Financing Recommendations. World Health Organization; 2015. Accessed January 20, 2021. https://www.who.int/hrh/ news/2015/CHW-Financing-FINAL-July-15-2015.pdf

24. Otiso L, Taegtmeyer M, Doyle V, et al. How Can We Achieve Universal Health Coverage With Quality? A Quality Improvement Model for Community Health, Policy Brief. U.S. Agency for International Development SQALE Program; 2018. Accessed January 20, 2021. http://usaidsqale.reachoutconsortium.org/ media/1051/sqale-brief-092018-final.pdf
25. Government of Republic of Kenya. Ministry of Health (MOH). Utilizing the Community Health Strategy to Respond to COVID 19 $\mathrm{MOH} ; 2020$. https://www.health.go.ke/wp-content/uploads/ 2020/04/Community-Response-to-COVID-2019_1.docx.pdf

26. Government of Republic of Kenya. Kenya Gazette Supplement Senate Bills, 2020. The Community Health Services Bill, 2020. Published April 3, 2020. Accessed January 20, 2021. http:// kenyalaw.org/kl/fileadmin/pdfdownloads/bills/2020/ CommunityHealthServicesBill_2020.pdf

27. Financing Alliance for Health. Community Health Financing Compendium. Financing Alliance for Health; 2017. Accessed September 1, 2020. https://staticl .squarespace.com/static/ $56 c 3 a 002 f 699 b b 071 \mathrm{ca} 52 \mathrm{~d} 81 / \mathrm{t} / 5 \mathrm{a} 7 \mathrm{~b} 806024 \mathrm{a} 6942 \mathrm{e} 853801$ $\mathrm{cl} / 1518043241543 / \mathrm{FAH}+$ Community + Health+Financing + Compendium+v1.0.pdf

28. Schaaf M, Fox J, Topp SM, et al. Community health workers and ac countability: reflections from an international "think-in". Int J Equity Health. 2018;17(1):66. CrossRef. Medline

29. World Health Organization (WHO). WHO Guideline on Health Policy and System Support to Optimize Community Health Worker Programmes. WHO; 2018. Accessed September 1, 2020. https:// apps.who.int/iris/bitstream/handle/10665/275474/ 9789241550369-eng.pdf

\section{Peer Reviewed}

Received: August 31, 2020; Accepted: January 7, 2021

Cite this article as: Hussein S, Otiso L, Kimani M, et al. Institutionalizing community health services in Kenya: a policy and practice journey. Glob Health Sci Pract. 2021;9(Suppl 1):S25-S31. https://doi.org/10.9745/GHSP-D-20-00430

() Hussein et al. This is an open-access article distributed under the terms of the Creative Commons Attribution 4.0 International License (CC BY 4.0), which permits unrestricted use, distribution, and reproduction in any medium, provided the original author and source are properly cited. To view a copy of the license, visit http://creativecommons.org/licenses/by/4.0/. When linking to this article, please use the following permanent link: https:// doi.org/10.9745/GHSP-D-20-00430 